\title{
Radical Intangibles: Materializing the Ephemeral
}

\author{
Sarah Kenderdine, Lily Hibberd, Jeffrey Shaw
}

\begin{abstract}
New materialism considers that the world and its histories are produced by a range of material forces that extend from the physical and the biological to the psychological, social and cultural. In recognizing that heritage is not held in objects alone, new materialism discourses echo definitions of intangible cultural heritage (ICH) enshrined in the 2003 UNESCO Convention for the Safeguarding of the Intangible Cultural Heritage. While museums understand the weight of responsibility when engaging with communities of practice, many still restrict the representation of archived $\mathrm{ICH}$ material to oral histories, object biographies, video and audio recordings of songs and performing arts. The technical complexities of archiving the 'live' perpetuate nineteenth-century museum display conventions, such as fixed-point perspectives and linear approaches to representation. To address this gap, we introduce 'computational museology', which brings a systems thinking approach to 'whole of environment' encoding. Such a framework unites, for instance, artificial intelligence with data curation, and ontology with visualization, as well as embodied participation through immersive and interactive interfaces. The implications of such a framework have yet to be fully theorized but it is evident that a new paradigm of materiality comprising 'radical intangibles' is taking shape in museums, which signals a break with both Western historiographic orthodoxies and hypothetical paradigms of tangible and intangible heritage. This article foregrounds the emergence of radical intangibles as crucial new digital materialities that are transforming reenacted and embodied practices. We demonstrate these radical intangibles in the in the discussion of two longitudinal curatorial projects based in China and Hong Kong: the first, 'Hong Kong Martial Arts Living Archive' (HKMALA) in collaboration with the International Goushou Association in Hong Kong, and the second, 'Remaking Confucian Rites' (RCR), undertaken in conjunction with Tsinghua University in Beijing. Both of these projects are significant for having taken up 'technologies of corporeality' - digital paradigms at the forefront of computer graphics, spatial and temporal modelling, and virtual reality. The powerful tools being developed across the two instances have begun to revolutionize $\mathrm{ICH}$ as a practice, a mode of transmission, and an object of study
\end{abstract}

Key words: digital museums; computational museology; new materialism; embodied historiography; virtual reality

\section{Introduction}

New digital materialities have, in recent years, become a vital apparatus for embodied practices of historical production and scholarship, from interpretation and documentation, to reperformance, display and transmission. What were once considered practices beyond representation or recording, the intangible realms of experience inherent to bodies (as they are conjoined with minds) are being transformed through computational processes into what we call 'radical intangibles'. We introduce the term radical intangibles to convey the paradigmatic change that digital materiality has wrought on objecthood and its ontologies, 
which are driving a new era of archiving lived and living cultures (Hui 2016). The application of these digital materialities to intangible, performed and embodied archives has the potential to create new forms of historiography and embodied knowledge transmission, both in quotidian cultural practice and in academic research (Balsamo 1995; Coté 2010; Kenderdine et al. 2014; Whatley et al. 2018).

This article pivots on the interplay of different forms of embodied heritage and the way that technologically-enabled scholarship and new media art practices are reshaping bodies as intangible objects of study. While museums are not the focal point of this text, they are the civic sites where computational approaches to the reperformance of the past come to life for the public. New digital museology and civic heritage approaches are reshaping museums into active sites of tacit experience, and opening up archives that can only be understood through bodily interfaces and interconnections, activating archives with 'liveness' through reperformable 'repertoires' (Auslander 1999; Schneider 2001; Taylor 2003; Parry 2007; Witcomb 2007; Taylor 2010). The novel radical intangibles we introduce here comprise performed and performing digital repertoires that are being produced behind the scenes, spawned at the intersection of tacit cultural practices and advanced computational processes (Kenderdine 2016).

Embodied cultural heritage can take many forms across diverse cultural practices, two definitions of which principally inform our discussion: intangible cultural heritage $(\mathrm{ICH}$, as defined by the 2003 UNESCO Convention) and reenactment heritage. ${ }^{1}$ These categories are examined through two extended scholarly projects that serve as case studies for this article: the 'Hong Kong Martial Arts Living Archive' (HKMALA) in collaboration with the International Goushou Association in Hong Kong (a longitudinal project with local kung fu master communities), and 'Remaking Confucian Rites' (RCR) undertaken in conjunction with Tsinghua University in Beijing. As collaborative interdisciplinary research projects, each of these endeavours have been undertaken by expert local researchers and/or practitioners HKMALA by the International Guoshu Association, and RCR at the Centre for Ritual Studies at Tsinghua University in Beijing, China - in partnership with the present coauthors' respective research laboratories, Sarah Kenderdine of the Laboratory for Experimental Museology $(\mathrm{eM}+)$ at the École Polytechnique Fédérale de Lausanne and Jeffrey Shaw at the Centre for Applied Computing and Interactive Media (ACIM), City University of Hong Kong. These two examples have been selected as innovations in scholarship that meld embodied acts with the computational powers of documentation, archive and reperformance, and show new materialities are bringing embodied archives into the public domain through interactive and immersive displays.

Although the digital preservation of intangible cultural heritage is promoted as a high-level priority in China, their documentation problems mirror those around the world (see Zhou et al. 2019). But new applied research into computational tools are changing the recording, expression and transmission of the performative social, arts, craft, ritual knowledge practices of $\mathrm{ICH}$ and reenactment heritage (Whatley et al. 2018). Through the two case studies, in this text we demonstrate the application of Sarah Kenderdine's novel methodology of 'computational museology', which unifies computer science with digital museology and the humanities (as described in part 1.2) to generate new modes of research for the study of $\mathrm{ICH}$ and reenactment cultures.

This article is presented in four parts: 1.1 Defining $\mathrm{ICH}$ and Reenactment Heritage: Globalized and Chinese Perspectives; 1.2 Computational Museology: A 'Systems Thinking' Model for New Materialities and Digital Embodied Heritage; 1.3 HKMALA: Digital Intangible Cultural Heritage and Hong Kong Martial Arts; and, 1.4 RCR: Reenactment and the Computational Remaking of the Ritual Chinese Body.

\subsection{Defining ICH and Reenactment Heritage: Globalized and Chinese Perspectives}

$\mathrm{ICH}$ and reenactment heritage are vast and complex topics that have both been extensively theorized (e.g. Kirshenblatt-Gimblett 2004; Kurin 2004; Smith 2006; McCalman and Pickering 2010; Schneider 2011; Smith 2011; Agnew et al. 2020). ${ }^{2}$ Yet, because concepts of intangible cultural heritage and reenactment can overlap, a number of key terms and notions need to be defined, insofar as the scope of this present publication permits. 
First of all, reenactments can be ICH instances, yet not all $\mathrm{ICH}$ is or can be reenacted. Reenactment practices stand apart from ICH more clearly as a form of 'reperformance' (after Taylor 2016) of a cultural practice that was discontinued at some point and which contemporary reenactors must therefore recreate. There is also confusing crossover between ICH and reenactment, especially due to the notion of 'living history'. This phrase is deployed, on one hand, in the context of a live dramatization event at museums or historic sites, and can include historical reenactment as one of its expressions (Jackson and Kidd 2011; Daugbjerg 2017). In contrast, the term 'living' in ICH literature implies that a heritage practice is alive because it has been perpetually maintained and performed by its cultural proprietors (KirshenblattGimblett 2004; Kurin 2004).

Furthermore, distinct from reenactment, $\mathrm{ICH}$ is a prominent international heritage governance policy and global discourse grounded in the 2003 UNESCO Convention for the Safeguarding of the Intangible Cultural Heritage. It is defined in the Convention as a performed culture that has been practised 'with a sense of identity and continuity' that is vanishing or threatened. ${ }^{3}$ The ICH Convention's wording implies that it aims to preserve traditional (minority) cultures, instead of all forms of human performative or social practice. But, as Kurin points out (2004: 69), it is not viable to totally exclude contemporary $\mathrm{ICH}$ iterations (e.g. street dancing, rap music). Meanwhile, critics of intangible cultural heritage policy and discourse, such as Harrison (2013) and Smith (2006), claim that UNESCO is at the root of 'authorized heritage discourses' as elements of modernity and globalization, through which universalizing, nationalistic and colonialist hegemonies are legitimized and reinforced.

As a practice, reenactment is said to have roots in ancient Greek and Roman eras, with the restaging of epic combats in the theatres of Athens and the Roman colosseum, and later in Medieval European religious pageants and reconstructed military victories (Cook 2020: 187; Daugbjerg 2020: 25), which underwent a kind of revival toward the end of the nineteenth century in Britain and its former colonial nations: the United States, Canada, and Australia (Bénichou 2017). In the mid-twentieth century, the term entered historical discourse as a way to describe the historian's mental visualization of the past (Collingwood 1946/2005; Dray 1995). Today, reenactment cultures proliferate in innumerably diverse iterations and cultural expressions, which can be studied from multiple angles, spanning ritual and ceremony, dance, sport, martial arts, theatre and performance, contemporary art, virtual reality and gaming, documentary and reality television, and cinema.

The academic field of reenactment studies is, moreover, relatively new but rapidly expanding, already encompassing the above humanities disciplines as well as performance and cultural studies, sociology, public history, and art theory, among others (see Rokem 2000; Agnew 2007; Rejack 2007; Vowinckel 2009; McCalman and Pickering 2010; Smith 2011; Schneider 2011; Johnson 2015; Franko 2018; Agnew et al. 2020). Despite being a subcategory of reenactment, ever since becoming widely popular during the $1990 \mathrm{~s}$, historical reenactment has become its most prominent genre. As a form of public history, it tends to reinforce memories and narratives of past events through realist aesthetics (though not always genuine) replica costumes/makeup, weapons/props, gesture/movements, scenography/landscaping, etc., that are supplanted into the present (see Gapps 2009a). Finally, historical reenactment has been critiqued for upholding hegemonic nationalist, imperialistic, and colonial narratives (Cook 2004; Agnew 2009; Gapps 2009b; Elliott 2019; Winter 2020).

In this article, we differentiate historical reenactment from the scholarly work of the Remaking Confucian Rites project. For one, due to their contrasting conceptual and political foundations, popular and academic reenactment tends to be, as Bénichou contends (2017: para. 15), fundamentally 'contradictory regimes'. Dreschke (2020) further emphasizes that in the field of ritual studies ${ }^{4}$ there is a sharp distinction between the popular social dimensions of historical reenactment and how it is used as a method of scholarship or an analytical tool. This view is echoed in European Martial Arts scholarship, which the authors say is 'rigorous and thorough' because it is grounded in applied scientific methodologies, akin to experimental archaeology (Jaquet et al. 2015: 16). But some aspects of the two approaches are common. For example, they share an aspiration for authenticity, and the reintegration of past experience through embodiment, affects and acts.

While this theoretical background informs our article, its primary focus is on the 
applied scholarship at the nexus of historiographic and computational museology specific to the sustenance of Hong Kong martial arts practices in the HKMALA, and secondly to the reenactment of Confucian Rites (RCR) in China. Ultimately, our aim is not to dichotomize theoretical classifications, but rather to illustrate the new knowledges arising from the application of computational museology to both $\mathrm{ICH}$ and reenactment heritage along with other scholarly digital methods and approaches that are facilitating the reperformance of embodied repertoires.

A few clarifications need to be made due to the cultural specificity of this article. Firstly, China is at the forefront of global $\mathrm{ICH}$ registration: since their 2004 ratification of the UNESCO Convention on Intangible Cultural Heritage, Chinese authorities have listed $40 \mathrm{ICH}$ elements. ${ }^{5}$ In contemporary post-socialist China, $\mathrm{ICH}$ is a significant discourse with its own interpretation, logic, and lineages, which an increasing number of scholars are theorizing from diverse Chinese standpoints, beyond a Western perspective (Gao 2014; Zhu 2014; You 2015; Kuah and Liu 2017; Maags and Svensson 2018). Importantly for this article, Chinese martial arts has also been embraced within the ICH framework (Daly 2010). Yet critics, including Chen (2015) and Wu (2012), address concerns that ICH is a burgeoning discursive power being used to bolster the Chinese Communist Party's nationalistic heritage policies. Accordingly, perceptions of the politics of Chinese cultural heritage are complex and contested, both within and outside of China (see Hou and Wu 2013; Yan 2016), for which theorizations from a Eurocentric outlook are often insufficient.

In China today, historical military, ritual, and martial arts reenactment is flourishing in amateur circles as well as in Chinese state-sponsored productions that restage historic battles at Culture Parks and historic sites (Bowman 2016; Li 2020). But, in contrast to ICH, until very recently there has been limited theorization of reenactment and its intensification in China today (e.g. Jaurès 2012; Zhang 2021), despite reenactment being used in documentary cinema throughout the latter part of the twentieth century to promote Chinese Communist Party narratives (Qian 2013).

These cultural and conceptual paradigms are vital to our two case studies; however, specific conceptual and technical methodologies underpin 'radical intangibles', which we now elaborate.

\subsection{Computational Museology: A 'Systems Thinking' Model for Radical Intangibles and Digital Embodied Heritage}

The most apparent presence of radical intangibles today is in the ubiquitous augmentation of materiality in digital forms (Hansen 2006; Parikka 2012; Reichert and Richterich 2015). The transformation of physical archives and objects into digital repositories has not only altered how people engage with the past, it has also changed the notion of objecthood itself (Hui 2016). Where material was once assumed to be bound to objects, the decoupling of the original from its copy and its integration into networked culture has created new avenues for the lives of bodies as virtual (if not actual) museum artefacts, where the sense of presence, or its thingness takes precedence over the thing itself (Dudley 2010; Hui 2016).

From the early 2000s, transversal approaches to this thinking began to be described as 'new materialisms' with the overarching aim of transcending orthodox mind/matter and nature/ culture dualisms, as well as the centrality of European humanism, in order to produce new agencies for materialities that foreground the social and its margins (see Latour 2005; Alaimo and Hekman 2008; Bennett 2010; Coole and Frost 2010). ${ }^{6}$ Performance studies scholars, such as Schneider (2015), have also established new materialisms for the body and its ephemeral productions. The materiality of digital objects has, however, been more difficult to theorize, Yuk Hui (2016: 3) reasoning that 'their thinghood and their existential status have rarely been brought into question' because 'computation relies on a new type of materiality'. In terms of making digital objects accessible beyond computed data, new museological interfaces and immersive systems are being created to facilitate the sensory and auratic encounters inherent to intangible and tacit heritage archives (Kenderdine and Yip 2019).

In order to forge an integration of the material and immaterial for embodied and performed cultural heritage enabled by computational tools, we introduce in this article Kenderdine's 
novel framework of 'computational museology'. Our objective here is to provide emergent scholarship with a unified praxis that combines fields of computer science (machine intelligence, data curation, ontology) with digital technologies and media art for embodied archives that enable participation (visualization, immersive and interactive interfaces) and the humanities more broadly. In linguistic terms, computational museology solves the problem of the lack of a common lexicon between computer science and the humanities, across reproduction, interoperability, gesture, ontology, or language (Hui 2016: 1).

Taking a 'systems thinking' approach, a number of theorists, including Jung and Love (2017), alongside Richmond (1994), have proposed that museums should operate as open and dynamic learning systems, as opposed to the closed status quo of compartmentalized and hierarchical systems. As cited in Kletchka (2019: 158) Anila, Foley and Quarcoopome, posit that systems thinking 'emphasize[s] interconnectedness, non-separability, nonlinearity, and polyvocality - from within the museum and without - allow[ing] new modes of interpretive planning to flourish in creating dynamic, inventive, and fresh installations of art'. Systems thinking underpins yet another major innovation, that of 'whole of environment' digitization, an approach that we define as the concurrent and integral linkage of many forms of digitized materiality - performance, objects, knowledge systems, representation, and participation through their interlocked and interoperable digitization.

As a tool for the radical intangibles of performed and embodied heritage, whole of environment encoding stands apart from other approaches to digitization because of its three uniquely enmeshed computational processes: data capture, computational modelling, and algorithmic reenactment (each defined below). These three operational components collectively generate the data for research into the analysis of features based on the form and style of physical movement in 3D space. Ultimately, these digitized 'acts' are made accessible in the form of interoperable and reusable embodied performance repertoires for scholars, expert practitioners, visualization designers, and publics.

The first of these components, data capture, entails the creation of assets through the digital encoding of live acts, using a range of technological capture processes. The primary pipeline for creating these assets are: green screen video capture, key frame pose extraction, motion capture data, animation, physically-based rendering and photogrammetry. These various digital tools work in tandem with conventional 3D modelling, photography, video (all types), and audio recordings of musicians or orators, as well as information arising from analysed or transcoded historical documents, in addition to the metadata of any of the above.

Motion capture is the primary data input technology for documenting embodied acts. The technology entails an array of infrared cameras to track a performer's body that is mapped with reflective markers (Fig. 1). For the advanced documentation of expressive tacit movement, the motion capture record of motion over time - or spatial/temporal modelling - produces continuous topological model datasets with unprecedented levels of detail that are particularly suited to documenting performed heritage. It has also been exploited for academic purposes by European martial arts scholars (see Channon and Jennings 2014; Farrer and WhalenBridge 2011). Because motion capture data can be subsequently reconstructed as a virtual 3D, interactive model of the performer's body, the technology is able to translate physical action into transferrable knowledge, especially when paired with mailable and navigable interactive platforms to support transmission (Rotman 2002; Kenderdine and Shaw 2017; Kenderdine 2021). As such, it is a crucial tool for documenting both $\mathrm{ICH}$ and reenacted forms of digital heritage today (Hamilton 2015; Karreman 2015).

The second element, computational modelling in the digital visualization sphere, harnesses advanced computer graphics technologies to create virtual visual (and acoustic) constructions of environments and objects, approaches that are in widespread use in computer imaging for architectural, archaeological astrophysics, and biological research, as well as gaming and many other visual domains (e.g. Rabinowitz 2015; Lock et al. 2018).

A number of researchers have employed movement modelling and visual and semantic ontologies to encode ICH for the performing arts. The EU Horizon 2020 project Terpsichore (2016-2020), for example, validated a framework for the affordable digitization, modelling, e-preservation, and presentation of folk dances and music (Doulamis et al. 2017). Another European Commission project, i-Treasures (2013-2017), applied multi-sensing capture and 
analytic technologies to develop a system to extract specific features or patterns of dance (Dimitropoulos et al. 2018). ${ }^{7}$ i-Treasures has also established 'MotionMachine', an open source library for the rapid prototyping, extraction and visualization of motion capture features, as well as a public platform and digital repository for research and education with game-like application. ${ }^{8}$

As our two case studies reveal, the visualization of computationally modelled embodied acts bear little comparison to other visualization approaches, primarily because the latter innovations build on their distinct modes of 'aesthetic transcription' (see 1.3) of embodied acts developed for dance, performance and media arts. The unique knowledge modelling for performance also embraces virtual production and sensory interfaced databases, which facilitate not only the recording of performers' bodies in motion over time but also the transcription of the tacit cultural knowledges that their actions express.

Algorithmic reenactment is the third novel component integral to whole of environment encoding. Defined as computational instructions, algorithms are intrinsic to digital media. Algorithms are also increasingly used as a tool of computer vision for (semi)automated video analysis and curation, such as the automatic extraction and interactive feature tracking of film/videos (Adams et al. 2002; Buchanan and Fitzgibbon 2006). The curation of algorithms broadly falls under the emerging domain of 'Computational Media Aesthetics' (Dorai and Venkatesh 2002). In the context of computational museology, algorithms combined with artificial intelligence are helping to open up otherwise abstract information in embodied knowledge archives and make it reperformable (e.g. Pizzo et al. 2019). The upshot of these approaches is that scholars of $\mathrm{ICH}$ and reenactment can both learn from and teach using these interactive databases (see 1.3 and 1.4 for further discussion).

While the ramifications of applying a whole of environment framework to encoding embodied acts has yet to be fully theorized, the two case studies we are about to describe show that a new paradigm of materiality comprising 'radical intangibles' is taking shape in the context of scholarly work on $\mathrm{ICH}$ and reenactment practices.

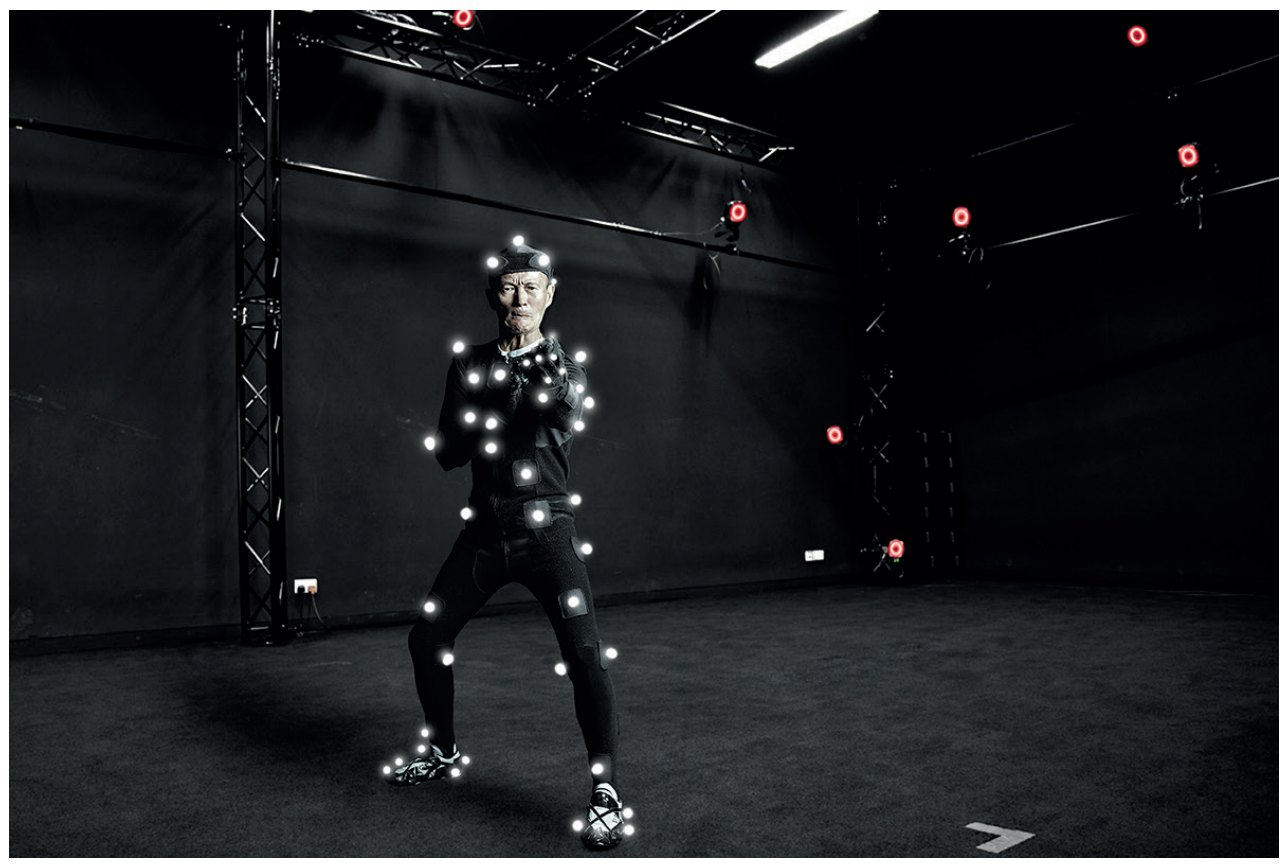

Figure 1: Kung Fu master in motion capture studio. Photo: Sarah Kenderdine. 


\subsection{HKMALA: Digital Intangible Cultural Heritage and Hong Kong Martial Arts}

Initiated in 2012 by the International Guoshu Association and City University of Hong Kong, HKMALA is an archival project that aims to redress the rapid waning of southern Chinese kung fu practices in recent decades (Chao et al. 2018). By the end of the twentieth century, a significant portion of traditional martial arts had already vanished, mainly due to their oppression alongside the expatriation of masters (many to Hong Kong) during the Chinese Cultural Revolution starting from 1969 (Amos 1983/1986: 280). While Hong Kong remains an active centre for elite kung fu practitioners, home to some of the most prominent martial artists in the world, the aging of the masters and the lack of means to record or transmit their expertise in their absence, threaten the total disappearance of the core traditions of kung fu. ${ }^{9}$ Furthermore, as martial arts scholars underscore, embodied practices cannot be learned from a book (Jaquet et al. 2015).

Chinese martial arts is traditionally a strict hierarchical system of master to student transmission. As Daly writes (2010: 357-61) the 'difficult and often arbitrary nature of passing on traditional kung fu', and the 'essence of the system' requires, according to one master Daly interviewed, at least ten years of strict commitment. For this reason, digital prostheses, ${ }^{10}$ are being developed as virtual embodied apparatuses in conjunction with computational interfaces for reperformance to create a computational chain of ICH knowledge transfer in the absence of master teachers (Chao et al. 2016).

The southern Chinese martial arts digital reconstruction that HKMALA has undertaken to date uniquely combines historical materials with creative visualizations building on advanced documentation processes for physical movement, including motion capture, motion-overtime analytics, 3D reconstruction, panoramic video, and 3D animation. The objective is to make these archives performative, to open up otherwise inaccessible embodied knowledge to practitioners, scholars, students, and enthusiasts of Hong Kong martial arts (Kenderdine and Shaw 2018).

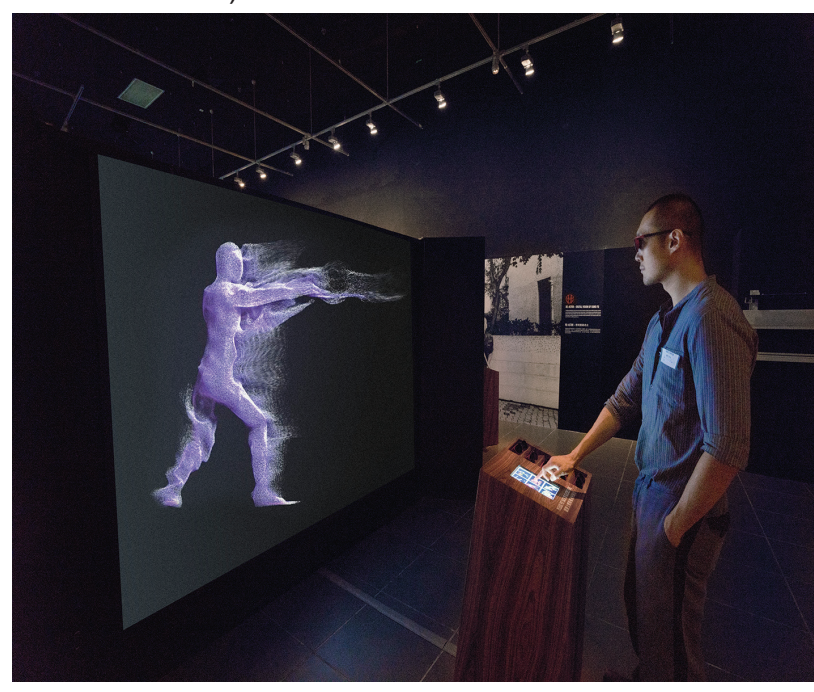

Figure 2: HKMALA, Re-Actor interactive installation in exhibition, 300 Years of Hakka Kung Fu, Heritage Museum Hong Kong, 2016. Photo: Sarah Kenderdine.
The HKMALA archive currently contains 19 styles by 33 elite practitioners, comprising the largest motion data archive of its kind in the world, which offers a unique capacity for translating physical action into transferrable knowledge (Kenderdine and Shaw 2017; 2018). Access to the HKMALA archive is made possible through 3D interfaces, life-size models, and interactive real-time applications in largescale virtual environments, designed atEPFL Laboratory for Experimental Museology $(\mathrm{eM}+)$ and City University of Hong Kong. Two HKMALA embodied system interfaces are presented here as illuminating examples: Re-Actor: Interactive Kung Fu Analytics, and Kung Fu Pose Matching.

Our first example from the HKMALA repertoire, Re-Actor: Interactive Kung Fu Analytics is presented in a five-metre diameter, six-sided virtual reality system called Re-Actor. The viewer can move around the two-metre-high hexagonal container, before choosing to interact with one of the six screens. Each active stereoscopic back projection screen features a motion capture recording of a unique kung fu taolu sequence performed by a kung fu master (Fig. 2). Created as mnemonic aids for kung fu novices, taolu are demarcated movement sequences used for practising and performing traditional Chinese martial arts styles, including spearplay, boxing, swordplay, 
and broadsword play. Rigorous, repeated practice of the pre-determined choreography taolu routines imprints this knowledge on the learner.

Each side of the Re-Actor has its own interactive control panel with a joystick that enables the viewer to shift between six different $3 \mathrm{D}$ visualizations of the taolu performance. Through colour and motion graphics, these six forms of documentation dynamically visualize the aesthetics and spatial-temporal dimensions underlying the movements of kung fu masters. Various rendering processes of motion-over-time analytics and 3D reconstruction enrich the motion capture data with the aesthetic and tacit knowledge of the master. They reveal the depth and array of intricate dynamics in the HKMALA repertoire; aspects of kung fu motion usually indiscernible to amateurs.

Ascribing meaning to performed acts in a way that is decipherable and reperformable is a critical challenge for embodied archives, but this is not a new problem. The translation of physical actions into a legible and communicable language has an extensive history in China in the form of martial arts manuals and ritual performance scripts dating back millennia, such as the Yili (see 1.4). In the West, the earliest complete systems of movement notion were the Laban/ LMA or Labanotation (Laban 1947/1994) and Benesh (1977). These techniques were later taken up in pioneering digital projects such as William Forsythe's Improvisation Technologies (1999).

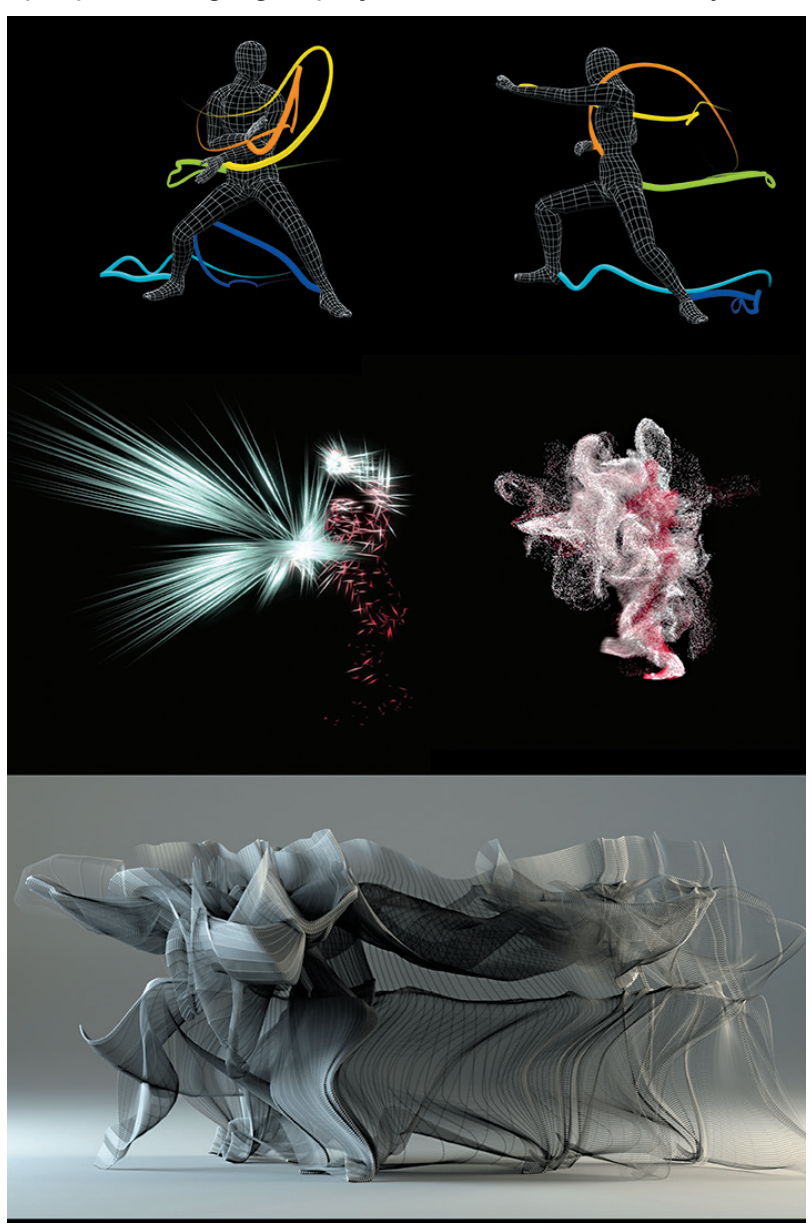

Figure 3: Kung Fu annotation and visualizations, 2016. Image: Sarah Kenderdine, Jeffrey Shaw and Tobias Gremmler.
As a tool for the visual analysis of choreographic dance forms, Improvisation Technologies features an overlay of motion graphics, animating lines on top of video images to visualize the underlying principles of Forsythe's movement (Ziegler 2016). From the end of the 1990s, leading interactive and immersive media artists (the authors of this article among them) theorized this technique as 'aesthetic transcription' (Brown et al. 2003; Kenderdine and Shaw 2009; Kenderdine 2016).

In the HKMALA project, aesthetic transcription is combined with interactive interfaces to support study, teaching and learning from its motion databases. In the case of Interactive Kung Fu Analytics, real-time visualization layers of visual transcription allow for interaction with the motion capture data itself, an effect that Karreman (2015: 37-8) has described as a form of recreating and extracting the capacity of a repertoire from that of its archive. This first HKMALA example thus serves as an important demonstration of the application of computational museology to the active archiving of intangible cultural heritage. Most important of all in terms of scholarship, such reflexive modes are designed to 
capture new data arising from expert reperformance to incorporate new knowledge, rather than a simple a priori analysis, thus keeping the essential 'liveness' intact in the performative $\mathrm{ICH}$ archive (Auslander 1999).

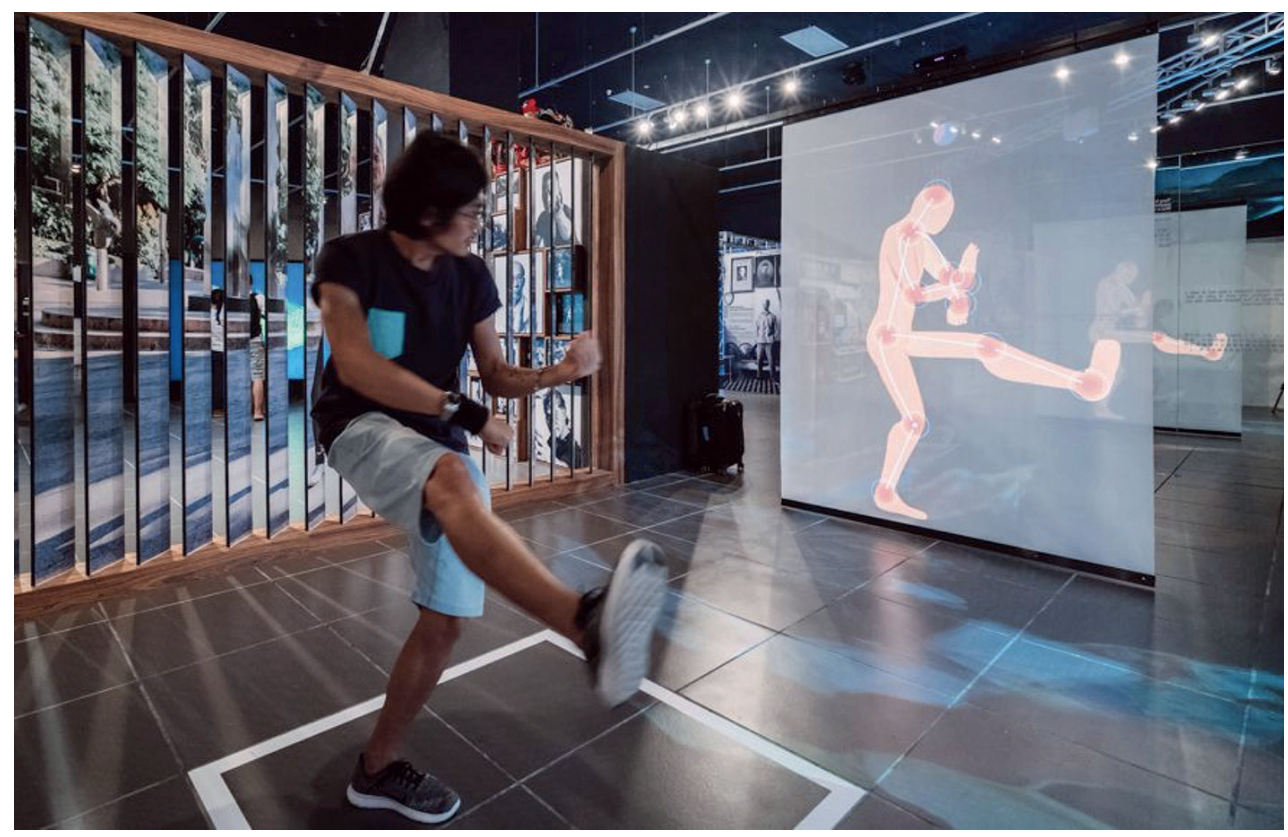

Figure 4: Kung Fu Pose Matching in 300 Years of Hakka Kung Fu, Heritage Museum Hong Kong, 2016. Photo courtesy of HKMALA.

The second HKMALA system is the Kung Fu Pose Matching installation, which was developed for he 2016 exhibition 300 YEARS OF HAKKA KUNG FU at the Heritage Museum Hong Kong and the 2018 exhibition Kung Fu Motion at EPFL ArtLab. The work comprises a lifesize, 1:1 scale video projection screen that shows a sequence of poses originally performed by a kung fu master (Fig. 4). Signage of two feet and a series of indicative images projected on a human-scale screen summon a single participant to step onto the square in front of the screen. Now within the detectable range of the motion sensors, the participant is shown a video sequence that guides them to match the pose of a kung-fu master by replicating their simplified movements. Built-in sensors capture the participant's movement - as soon as their body and limbs have configured the same position of the master, the video screen flashes to suggest that the task is complete, subtly playing on the reward credo of video game constructs.

Kung Fu Pose Matching builds on imitative pedagogic features of pre-existing gaming technologies, such as Kinect, and combines them with virtual and mixed reality technologies that have been shown to be powerful conduits for embodied knowledge transmission (Chan et al. 2011; Lindgren and Johnson-Glenberg 2013). Moreover, because kung fu is imitative, iterative and physically interactive learning is vital to its mastery (Komura et al. 2006). As such, during 2018, Sarah Kenderdine and Denis Hauw of the University of Lausanne (UNIL) completed an EPFL/UNIL funded study examining the transmission of embodied knowledge through 'imitation'. As a prototype of the eventual exhibited installation, the aim was to test the efficacy of virtual reality to engender enactivist (or cognition through doing, see Sumara and Davis 1997) models of learning for knowledge transfer from digital-master to humannovice. Realized in controlled conditions with sports and cognitive scientists, the evaluation documented some improvement in participants' movements with repetition, as the gap between the master and novice's speed and positioning of movements narrowed. 
While there is no guarantee that a novice engaged in copying the kung fu master's movements will either comprehend, access, or acquire the tacit expertise they are replicating, the novel conjunction of gaming platform with motion capture archives opens an avenue for transmission that is more likely to engage beginners. Additionally, in contrast with classic Kinect console games like Dance Central, the use of sensor technology in this installation does not result in empty gestures nor a purely ludic endgame. Digital human movement depth sensors have already been applied and tested in ICH documentation (e.g. Protopapadakis et al. 2017). As such, despite the difficulties associated with apprehending ephemeral embodied acts, the installation is an archetype for avatar-based transmission modes of $\mathrm{ICH}$.

The final and most crucial difference between mainstream mimetic simulation games and their application in the cultural heritage sector and Kung Fu Pose Matching is that threatened cultural heritage archives underpin the latter; a mission that is all the more crucial in the instance of broken transmission, such as for the revival of Confucian ritual practices today.

\subsection{RCR: Reenactment and the Computational Remaking of the Ritual Chinese Body}

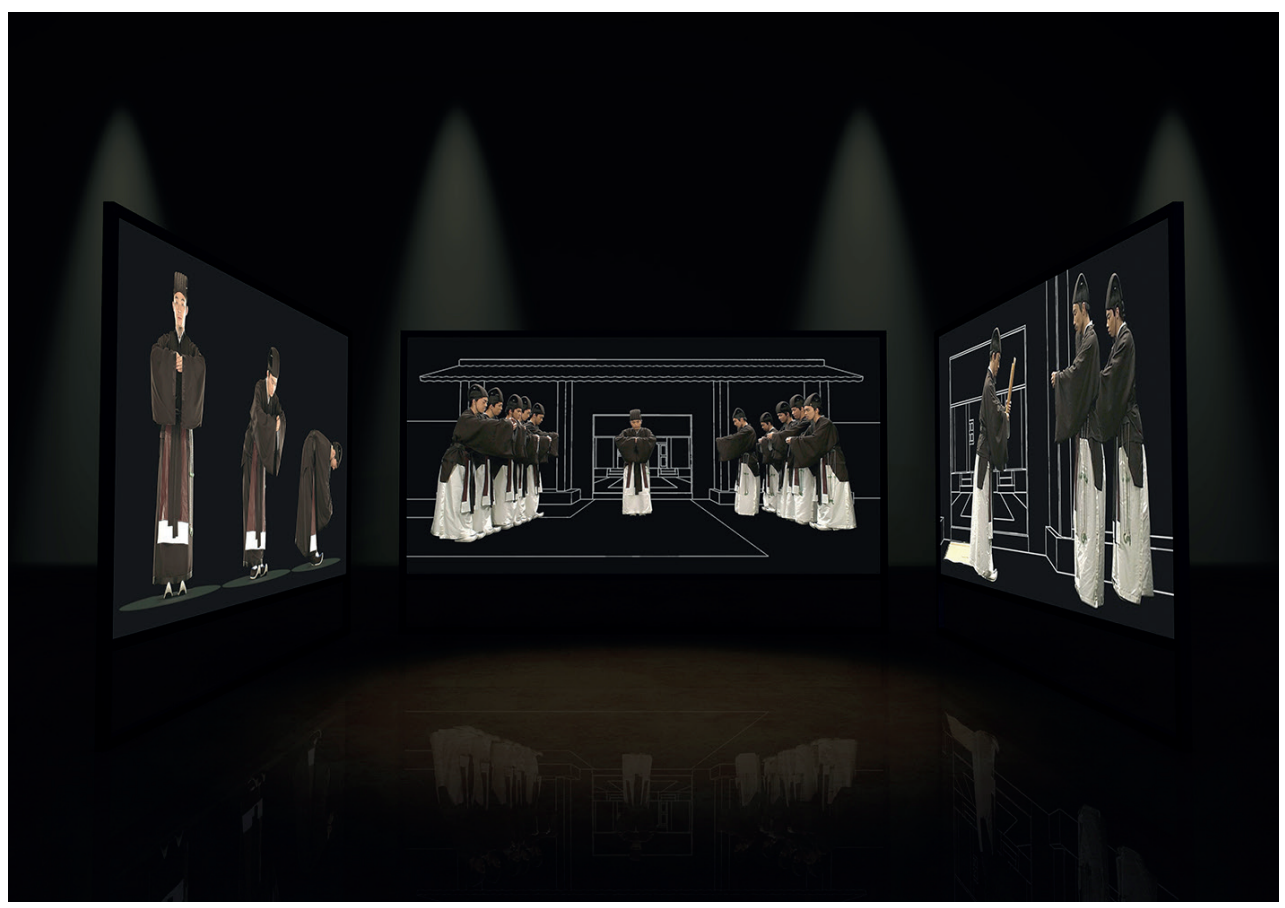

Figure 5: Remaking Confucian Rights, Three-screen installation of the capping ceremony, 8th Triennial of Contemporary Art, Ljubljana, Slovenia, 2016. Image: Paul Nichola

Remaking Confucian Rites (RCR) is a major research project led by Professor Peng of Tsinghua University, Beijing, in collaboration with City University of Hong Kong, Lia Jin Hall, and École Polytechnique Fédérale de Lausanne (EPFL). At the core of this project is the renewed philological study of the Yili 儀禮 (Book of Etiquette and Rites), which describes rituals recorded by disciples of Confucius in the fifth century BCE. Yili was a core text in the Confucian canon and Chinese civilization for thousands of years. ${ }^{11}$ It is founded on the Confucian cosmology, theory and ethics of li. As a moral code embedded in bodily, performed practices, li realized through ritual acts. Following the revolution of the National Republic in 1911, then during the Cultural Revolution from 1966 to 1971, a critical breakdown occurred in the cultural practice and social transmission of Confucian Rites and thus also li (Billioud and Thoraval 2015). 
Today, Remaking Confucian Rites is fashioning essential new archives to support Confucian embodied knowledge systems, the latter being a topic of inquiry for several decades (Wei-Ming 1992; Ott 2017). The Yili was notably designed as a "performance manual' for practical self-cultivation in relation to family, state and cosmos. The RCR project pivots on a reconstruction ${ }^{12}$ process combining the line-by-line 'close' reading of the text, the study of diverse philological and archaeological sources. Based on this research, a script for reenactment has been created with music and dialogue. It also includes lists of props, produced from cross-referencing archaeological and textual materials for making replica architectural elements, ritual objects, and costumes.

The Yili contains a total of 17 rites. In this article we focus specifically on the fifth rite, the Archery Ceremony Xiangshe li (Rites of the Provincial Archery Competition) for two reasons. One, it permits an analysis of the RCR's novel methodology for the renewed reperformance and transmission of Confucian Rites today, which couples reenactment with advanced digital documentation forms, along with interactive and immersive media art experiences Fig. 5). Two, ritual archery is one of the few methods that remains linked to the traditions of practising and transmitting $l i$, as traditional archery was assimilated within contemporary Chinese society (Selby 2000; Ma and Ma 2004; Peng and Han 2016).13

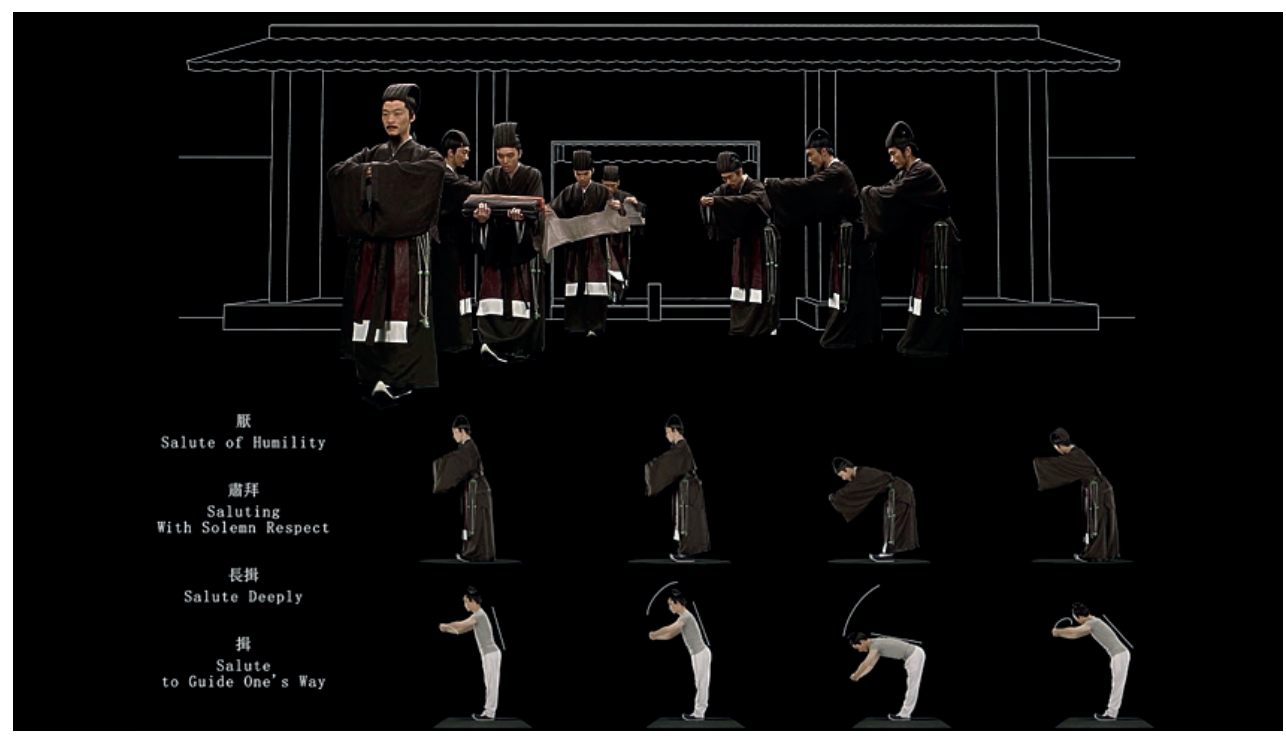

Figure 6: Multimodal recordings and annotation of the capping ceremony, Remaking Confucian Rites. Image courtesy of Centre for Chinese Ritual Studies, Tsinghua University.

In 2012, Peng joined with Kenderdine and Shaw to embark on the digital reconstruction and recording of the Archery Rite reenactment. An almost full-scale set of the ritual temple described in Yili was constructed in a sound studio in Beijing, and the entire ceremony was shot over several months with a troupe of thirty elite actors from the Beijing Opera at professional cinema quality (totalling about eight hours' viewing time). The latest Hollywood green screen techniques were also deployed for the eventual digital reproduction of the scenery around the temple complex.

While the photoreal representation of the location was prioritized, the main focus of the shoot was on the ritual behaviour of the actors. The actors' movements in the real space were documented using motion capture and tracked in 3D, building on the unique aesthetic and movement transcription techniques developed for HKMALA. State-of-the art 3D imaging was also employed, such as panoramic 3D and 360-degree photography, and spherical 360-degree videography. These high-resolution recordings have been used for in-depth statistical analysis, then transcribed into animations and annotated and real-time visualization 
layers of text, colour, and motion graphics. Overlaid on the videos, these analyses convey the spatial and temporal features of the motion, displayed in a digital application specially created for the RCR project (Fig. 6).

The underlying database is the most important attribute of all for the RCR team, who have been populating it with annotations of past performances and other archery rites. ${ }^{14}$ In addition to this video documentation, the Archery Rite archive contains photographs, drawings, and text concerning attire, ceremonial objects, ritual gestures, as well as academic commentary. Because they can revisit, replay and review the live and annotated videos, RCR scholars can make a deeper excavation of the Archery Rite reenactment, and build on this knowledge with each reperformance. The RCR team are also exploiting the data archive to address otherwise unsolvable problems and test hypotheses drawn from the ritual literature, by comparing them with the performance of the ritual acts to mine what Lia Jin Hall and director Tsong-Zung Chang call the 'molecular structure' of $l i{ }^{15}$ Digitally augmented in this way, scholarly reenactment generates ontologically intense knowledge because its liveness as well as more abstract ritual qualities can be contextualized in a wholly live and yet remakeable encoded world.

The large-scale operation to record, encode and display the tacit contents of the Archery Rite reveals some of the potential for its renewed transmission through virtual interaction, presence and immersion within Confucian ritual knowledge systems. As it couples reenactment with the power of computational modelling, this approach could unlock and revivify the radical intangibles of $/ i$ embedded in the ritual expressions of the modern Confucian body.

\section{Conclusion}

In recent decades, computational advances in data science and graphics modelling have been successfully applied to material cultural heritage, including 3D scanning and displays using immersive and interactive technologies to enliven immutable objects online and in museums. Unseen, behind the public presentation of civilization through objects, are archives of embodied experience. Apart from the challenges of display, these archives must first of all be elicited, recorded, and encoded, which is all the more difficult in situations where the repositories and transmitters of that knowledge have been ruptured or are at risk, which is the current concern of both the HKMALA and Remaking Confucian Rites projects.

As we have outlined in this article, our work to inaugurate computational museology intends to address the challenges of documenting and transmitting $\mathrm{ICH}$ and reenactment through the conjoining of data science, immersive technologies, and new museology. Computational museology pivots moreover on 'technologies of corporeality' - computer graphics, spatial and temporal modelling, and virtual reality - with multiple modalities and digital prostheses for the body as the principal repertoire and holder of knowledge, thus encoding acts and making them reperformable. Finally, both the HKMALA and RCR projects are examples of how computational museology can address the politics attached to the body in Chinese cultural heritage. They demonstrate how radical intangibles are bridging the gap between emerging forms of digital archiving and their modes of transmission in both $\mathrm{ICH}$ and reenactment approaches, with the greater aspiration of reconciling the Chinese body past and present.

Received: 5 October 2020 Finally accepted: 1 June 2021

\section{Notes}

1 UNESCO, 'Text of the Convention for the Safeguarding of the Intangible Cultural Heritage', 2003. https://ich.unesco.org/en/convention, accessed 9 June 2021. See also UNESCO, 'China and the 2003 Convention', n.d. https://ich.unesco.org/en/state/china-CN, accessed 9 June 2021.

2 In terms of materiality and the digital in museums, there is much work to do to break old binaries of representation, systemic racism, and Westernized and imperialist structures. See Lonetree 2012; Fischer et al. 2017; Vawda 2019; Chipangura and Chipangura 2020.

3 UNESCO, 'Convention for the Safeguarding of the Intangible Cultural Heritage', art 2.2. 
4 Rites or rituals are formalized or performed ceremonial acts, arising either from long secular tradition or sacred orders, see Schechner 1993; Bell 1997.

5 UNESCO, 'China and the 2003 Convention'.

6 Since the late twentieth century, multiple strands of critical theory have been concerned with expanding the ethics of the material and social being, spanning feminism (Haraway 1985; Grosz 1994), philosophy and social anthropology (Latour 2005), queer, posthuman, cultural and performance studies (Barad 2003; Chen 2012; Braidotti 2013), and intersectional, First Nations, decolonial, and critical race theorists (Crenshaw 1991; Sundberg 2014; Todd 2016).

7 European Commission, 'i-Treasures: Capturing the Intangible Cultural Heritage and Learning the Rare Know-How of Living Human Treasures', EU Commission blog, 12 July 2016. https://ec.europa.eu/digital-single-market/en/blog/i-treasures-capturing-intangiblecultural-heritage-and-learning-rare-know-how-living-human, accessed 9 June 2021.

8 European Commission, 'i-Treasures', 2016.

9 Despite the recent 'explosion of "traditional" kung fu schools and academies in China' resulting from 'government encouragement' (Daly 2010: 354) it cannot repair the break in transmission without masters.

10 On protheses as vessels of cultural memory, see Lury 1998; Landsberg 2004; Sobchack 2006; Stobiecka 2020.

11 The Yili manuscript is available in Chinese as Yili zhushu (1957) Zheng, X. and Jia, G., Beijing: Zhonghua Book Company.

12 In academic contexts, the term reconstruction is sometimes used instead of reenactment, for example in Historical European Martial Arts (HEMA), where it distinguishes rigorous, scientific reproduction of performed cultures from the popular activity of reenactment (Jaquet et al. 2015). Reconstruction also connotes the fabrication of reality based on tangible evidence, as in forensic architecture (Gallanti 2020: 80), or forensic crime scene investigation, a field that also differentiates the involvement of human actors as reenactment.

13 See also Lin Peng, 'Practice Gives Deeper Understandings than Theoretical Readings. Why is the Reenactment of Confucian Rites Critical?', Guang Ming Daily, 12 December 2020. https://epaper.gmw.cn/gmrb/html/2020-12/16/nw.D110000gmrb_20201216_2-15. htm, accessed 9 June 2021.

14 Peng, 'Practice Gives Deeper Understandings than Theoretical Readings'.

15 As T.Z. Chang describes in his presentation at 'Deep Time Machine II: Remaking Confucius Rites', Potential Spaces Conference, Karlsruhe: ZKM, 2017. https://www.youtube.com/ watch?v=ry2leciY58Q, accessed 9 June 2021.

\section{References}

Adams, B., Dorai, C. and Venkatesh, S. (2002) 'Toward Automatic Extraction of Expressive Elements from Motion Pictures: Tempo', IEEE Trans. Multimedia, 4 (4) 472-81.

Agnew, V. (2007) 'History's Affective Turn: Historical Reenactment and its Work in the Present', Rethinking History, 11 299-312. doi: 10.1080/13642520701353108.

(2009) 'Epilogue: Genealogies of Space in Colonial and Postcolonial Reenactment', in Vanessa Agnew and Jonathan Lamb (eds) Settler and Creole Reenactment, 294318, London: Palgrave Macmillan. 
Agnew, V., Lamb, J. and Tomann, J. (eds) (2020) The Routledge Handbook of Reenactment Studies, London: Routledge.

Alaimo, S. and Hekman, S.J. (eds) (2008) Material Feminisms, Bloomington: Indiana University Press.

Amos, D.M. (1983/1986) Marginality and the Hero's Art: Martial Artists in Hong Kong and Guangzhou, Los Angeles: University of California.

Auslander, P. (1999) Liveness: Performance in a Mediatized Culture, New York: Routledge.

Balsamo, A. (1995) 'Forms of Technological Embodiment: Reading the Body in Contemporary Culture', in Mike Featherstone and Roger Burrows (eds) Cyberspace/ cyberbodies/cyberpunk: Cultures of Technological Embodiment, 215-38, London: Sage Publications.

Barad, K. (2003) 'Posthumanist Performativity. Toward an Understanding of How Matter Comes to Matter', Signs, 28 (3) 801-31.

Bell, C. (1997) Ritual: Perspectives and Dimensions, New York: Oxford University Press.

Benesh, R. (1977) Reading Dance: The Birth of Choreology, London: Souvenir Press.

Bénichou, A. (2017) 'Introduction: Le reenactment ou le répertoire en régime intermédial', Intermédialités, 28/29 unpaginated. doi: doi/10.7202/1041075ar.

Bennett, J. (2010) Vibrant Matter: A Political Ecology of Things, Durham NC; Duke University Press.

Billioud, S. and Thoraval, J. (2015) The Sage and the People, The Confucian Revival in China, Oxford and New York: Oxford University Press.

Bowman, P. (2016) 'Making Martial Arts History Matter', The International Journal of the History of Sport, 33 (9) 915-33. doi: doi/10.1080/09523367.2016.1212842.

Braidotti, R. (2013) The Posthuman, Cambridge: Polity.

Brown, N., Del Favero, D., Shaw J. and Weibel, J. (2003) 'Interactive Narrative as a Multitemporal Agency', in Jeffrey Shaw and Peter Weibel (eds) Future Cinema: The Cinematic Imaginary After Film, 312-5, Cambridge, MA: MIT Press.

Buchanan, A. and Fitzgibbon, A. (2006) 'Interactive Feature Tracking using k-d Trees and Dynamic Programming', Proceeds, Computer Vision Pattern Recognition 1626-33.

Chan, J.C., Leung, H., Tang, J.K. and Komura, T. (2011) 'A Virtual Reality Dance Training System using Motion Capture Technology', IEEE Transactions on Learning Technologies, 4 (2) 187-95.

Channon, A. and Jennings, G. (2014) 'Exploring Embodiment through Martial Arts and Combat Sports: A Review of Empirical Research', Sport in Society: Cultures, Commerce, Media, Politics, 17 (6) 77389. doi: 10.1080/17430437.2014.882906.

Chao, H., Delbridge M., Kenderdine, S., Nicholson, L. and Shaw, J. (2018) 'Kapturing Kung Fu: Future Proofing the Hong Kong Martial Arts Living Archive', in Sarah Whatley, Rosamaria K. Cisneros and Amalia Sabiescu (eds) Digital Echoes: Spaces for Intangible and Performance-based Cultural Heritage, 249-64, London: Palgrave Macmillan. 
Chao, H., Shaw, J. and Kenderdine, S. (eds) (2016) 300 Years of Hakka Kung Fu: Digital Vision of its Legacy and Future, Hong Kong: International Guoshu Association.

Chen, M.Y. (2012) Animacies: Biopolitics, Racial Mattering, and Queer Affect, Durham NC: Duke University Press.

Chen, Z. (2015) 'For Whom to Conserve Intangible Cultural Heritage: The Dislocated Agency of Folk Belief Practitioners and the Reproduction of Local Culture', Asian Ethnology, 74 (2) 307-34.

Chipangura, N. and Chipangura, P. (2020) 'Community Museums and Rethinking the Colonial Frame of National Museums in Zimbabwe', Museum Management and Curatorship, 35 (1) 36-56. doi: doi.org/10.1080/09647775.2019.1683882.

Collingwood, R.G. (1946/2005) The Idea of History, Jan van der Dussen (ed) Oxford: Oxford University Press.

Cook, A. (2004) 'The Use and Abuse of Historical Reenactment: Thoughts on Recent Trends in Public History', Criticism, 46 (3) 487-96.

(2020) 'Practices of Reenactment', in Vanessa Agnew, Jonathan Lamb, and Juliane Tomann (eds) The Routledge Handbook of Reenactment Studies, 187-90, London: Routledge.

Coole, D. and Frost, S. (eds) (2010) New Materialisms: Ontology, Agency, and Politics, Durham and London: Duke University Press.

Coté, M. (2010) 'Technics and the Human Sensorium: Rethinking Media Theory through the Body', Theory \& Event, 13 (4).

Crenshaw, K. (1991) 'Mapping the Margins: Intersectionality, Identity Politics, and Violence against Women of Color', Stanford Law Review, 43 (6) 1241-99. doi: $10.2307 / 1229039$.

Daly, P. (2010) 'Fighting Modernity: Traditional Chinese Martial Arts and the Transmission of Intangible Cultural Heritage', in Patrick Daly and Tim Winter (eds), Routledge Handbook of Heritage in Asia, 350-63, New York: Routledge.

Daugbjerg, M. (2017) 'Being There: Time Travel, Experience and Experiment in Reenactment and "Living History" Performances', in Bodil Petersson and Cornelius Holtorf (eds) The Archaeology of Time Travel: Experiencing the Past in the 21st Century, 159-76, Oxford: Archaeopress.

(2020) 'Battle', in Vanessa Agnew, Jonathan Lamb and Juliane Tomann (eds) The Routledge Handbook of Reenactment Studies, 25-9, London: Routledge.

Dimitropoulos, K. et. al. (2018) 'A Multimodal Approach for the Safeguarding and Transmission of Intangible Cultural Heritage: The Case of $i$-Treasures', IEEE Intelligent Systems, 33 (6) 3-16.

Dorai, C. and Venkatesh, S. (eds) (2002) Media Computing: Computational Media Aesthetics, Boston, MA: Springer.

Doulamis, A., Voulodimos, N., Doulamis, N., Soile, S. and Lampropoulos, A. (2017) 'Transforming Intangible Folkloric Performing Arts into Tangible Choreographic Digital Objects: The Terpsichore Approach', Proceedings 12th International Joint Conference on Computer Vision, Imaging and Computer Graphics Theory and Applications, 5 451-60. doi: 10.5220/0006347304510460 . 
Dray, W.H. (1995) History as Re-Enactment: R.G. Collingwood's Idea of History, Oxford: Clarendon Press.

Dreschke, A. (2020) 'Ritual', in Vanessa Agnew, Jonathan Lamb and Juliane Tomann (eds) The Routledge Handbook of Reenactment Studies, 202-5, London: Routledge.

Dudley, S.H. (2010) 'Museum Materialities: Objects, Sense and Feeling', in Sandra Dudley (ed) Museum Materialities: Objects, Engagements, Interpretations, 1-17, London and New York: Routledge.

Elliott, M. (2019) 'Decolonial Re-enactments?', Third Text, 33 (4-5) 631-50. doi: 10.1080/09528822.2019.1655893.

Farrer, D.S. and Whalen-Bridge, J. (2011) 'Introduction: Martial Arts, Transnationalism and Embodied Knowledge', in D.S. Farrer and John Whalen-Bridge (eds) Martial Arts as Embodied Knowledge: Asian Traditions in a Transnational World, 1-25, Albany: State University of New York Press.

Fischer, D., Anila, S. and Moore, P. (2017) 'Coming Together to Address Systemic Racism in Museums', Curator 60 (1) 23-31. doi: 10.1111/cura.12191.

Forsythe, W. (1999) Improvisation Technologies. A Tool for the Analytical Dance Eye (CDROM), Karlsruhe, Germany: ZKM.

Franko, M. (ed) (2018) The Oxford Handbook of Dance and Reenactment, Oxford, Oxford University Press.

Gallanti, F. (2020) 'Forensic Architecture', in Vanessa Agnew, Jonathan Lamb and Juliane Tomann (eds) The Routledge Handbook of Reenactment Studies, 79-83, London: Routledge.

Gao, B. (2014) 'How Does Superstition Become Intangible Cultural Heritage in Postsocialist China?', Positions (Asia Critique), 22 (3) 551-72.

Gapps, S. (2009a) 'Mobile Monuments: A View of Historical Reenactment and Authenticity from Inside the Costume Cupboard of History', Rethinking History, 13 (3) 395-409.

(2009b) 'Black-Facing for the Explorers', in Vanessa Agnew and Jonathan Lamb (eds) Settler and Creole Re-Enactment, 208-20, New York: Palgrave MacMillan.

Grosz, E. (1994) Volatile Bodies: Towards a Corporeal Feminism, Sydney: Allen and Unwin.

Hamilton, K. (2015) 'Mapping Motion II: Motion Capture and the Visualisation of Dance', Proceedings of the Conference on Electronic Visualisation and the Arts, 46-55.

Hansen, M.B.N. (2006) Bodies in Code: Interfaces with Digital Media, New York: Routledge.

Haraway, D. (1985) 'A Manifesto for Cyborgs: Science, Technology, and Socialist Feminism in the 1980s', Socialist Review, 15 (2) 65-107.

Harrison, R. (2013) Heritage: Critical Approaches, New York, NY: Routledge.

Hou, S. and Wu, Z.J. (2013) 'The Discursive Approach to Heritage Studies: Theory, Method and Prospect', Southeast Culture, 3 6-13.

Hui, Y. (2016) On the Existence of Digital Objects, Minneapolis: University of Minnesota Press. 
Jackson, A. and Kidd, J. (eds) (2011) Performing Heritage: Research, Practice and Innovation in Museum Theatre and Live Interpretation, Manchester: Manchester University Press.

Jaquet, D., Sorenson, C.F. and Cognot, F. (2015) 'A Crossroad between Academic Research, Martial Heritage Re-creation and Martial Sport Practices', Acta Periodica Duellatorum 3 5-35. https://archive-ouverte.unige.ch/unige:56063.

Jaurès, A. (2012) 'Le tourisme rouge en Chine: véritable engouement ou carte forcée?', Monde chinois, 29 (1) 88-101.

Johnson, K. (2015) 'Rethinking (Re)doing: Historical Re-enactment and/as Historiography', Rethinking History, 19 (2) 193-206.

Jung, Y. and Love, A.R. (eds) (2017) Systems Thinking in Museums: Theory and Practice, Lanham, MD: Rowman and Littlefield.

Karreman, L. (2015) 'Worlds of MoCap', Performance Research, 20 (6) 35-42. doi: https:// doi.org/10.1080/13528165.2015.1111049.

Kenderdine, S. (2016) 'Embodiment, Entanglement and Immersion in Digital Cultural Heritage', in Susan Schreibman, Ray Siemens and John Unsworth (eds) A New Companion to Digital Humanities, 22-41, Chichester: John Wiley and Sons, Ltd.

(2021, in press) 'Prosthetic Architectures of the Senses: Museums and Immersion', in Martine Beugnet and Lily Hibberd (eds. dossier) 'Absorbed in Experience: New Perspectives on Immersive Media', Screen, 61 (4).

Kenderdine, S., Chan, L.K.Y. and Shaw, J. (2014) 'Pure Land: Futures for Embodied Museography', Journal on Computing and Cultural Heritage, 7 (2), 1-15.

Kenderdine, S. and Shaw, J. (2009) 'New Media in Situ: The Re-socialisation of Public Space', International Journal of Arts and Technology, 2 (4) 258-76. doi: doi. org/10.1504/IJART.2009.029235.

(2017) 'Archives in Motion. Motion as Meaning', in Oliver Grau (ed) Museum and Archive on the Move: Changing Cultural Institutions in the Digital Era, 211-33, Berlin: De Gruyter. doi: 10.1515/9783110529630-014

(2018) 'The Museological Re-enactment of Lingnan Hung Kuen', in Hing Chao (ed) Across the Century: Kung Fu Narratives in Cinema and Community, 137-59, Hong Kong: City University of Hong Kong Press.

Kenderdine, S. and Yip, A. (2019) 'The Proliferation of Aura: Facsimiles, Authenticity and Digital Objects', in Kirsten Drotner, Vince Dziekan Ross Parry and Kim Christian Schrøder (eds) The Routledge Handbook to Museum Communication, 274-89, Abingdon: Routledge.

Kirshenblatt-Gimblett, B. (2004) 'Intangible Heritage as Metacultural Production', Museum International, 56 (1/2) 52-65.

Kletchka, D.C. (2019) 'Review: Systems Thinking in Museums: Theory and Practice, edited by Y. Jung and A.R. Love', Journal of Arts Management, Law, and Society, 49 (2) 151-2. doi: 10.1080/10632921.2018.1517066.

Komura, T., Lam, B., Lau, R. and Leung, H. (2006) 'e-Learning Martial Arts', in Liu, Wenyin, $\mathrm{Li}$, Quing, Lau, and Rynson W.H. (eds), Advances in Web Based Learning - ICWL 2006 in series Lecture Notes in Computer Science vol. 4181 239-48, Heidelberg: Springer. 
Kuah, K.E. and Liu, Z. (2017) Intangible Cultural Heritage in Contemporary China: The Participation of Local Communities, London: Routledge.

Kurin, R. (2004) 'Safeguarding Intangible Cultural Heritage in the 2003 UNESCO Convention: A Critical Appraisal', Museum International, 56 66-77.

Laban, R. (1947/1994) The Mastery of Movement, trans. Challet-Haas, J. and Bastien, M., London: Macdonald and Evans.

Landsberg, A. (2004) Prosthetic Memory: The Transformation of American Remembrance in the Age of Mass Culture, New York: Columbia University Press.

Latour, B. (2005) Reassembling the Social. An Introduction to Actor Network Theory, Oxford: Oxford University Press.

Li, Y. (2020) 'A Reenactment of the Chinese Cultural Revolution in the 2020 Election', Epoch Times, November 21.

Lindgren, R. and Johnson-Glenberg, M. (2013) 'Emboldened by Embodiment: Six Precepts for Research on Embodied Learning and Mixed Reality', Educational Researcher 42 (8) 445-52. doi: https://doi.org/10.3102/0013189X13511661.

Lock, J.G., Filonik, D., Lawther, R., Pather, N., Gaus, K., Kenderdine, S. and Bednarz, T. (2018) 'Visual Analytics of Single Cell Microscopy Data using a Collaborative Immersive Environment', VRCAl'18 Proceedings 16th SIGGRAPH, 1-4. doi: 10.1145/3284398.3284412.

Lonetree, A. (2012) Decolonizing Museums: Representing Native America in National and Tribal Museums, Chapel Hill: University of North Carolina Press.

Lury, C. (1998) Prosthetic Culture: Photography, Memory and Identity, London and New York: Routledge.

Ma, M. and Ma, L. (2004) 'Pursuing the Lost Chinese "Archery": Impressions on Xie Sufang's 'Chinese Archery"', The Journal of Sport History and Culture, 6 71-2.

Maags, C. and Svensson, M. (2018) Chinese Heritage in the Making: Experiences, Negotiations and Contestations, Amsterdam: Amsterdam University Press.

McCalman, I. and Pickering, P.A. (eds) (2010) Historical Reenactment: From Realism to the Affective Turn, Basingstoke: Palgrave Macmillan.

Ott, M. (2017) 'Confucius' Embodied Knowledge', Asian Studies, 5 (2) 65-85. doi. org/10.4312/as.2017.5.2.65-85.

Parikka, J. (2012) 'New Materialism as Media Theory: Medianatures and Dirty Matter', Communication and Critical/Cultural Studies, 9 (1) 95-100.

Parry, R. (2007) Recoding the Museum: Digital Heritage and the Technologies of Change, London: Routledge.

Peng L. and Han, B. (2016) 'Early Stages of Ritual Archery', Lishe Chujie, Beijing: People's Sports Publishing House of China.

Pizzo, A., Lombardo, V. and Damiano, R. (2019) 'Algorithms and Interoperability between Drama and Artificial Intelligence', TDR: The Drama Review, 63 (4) 14-32. 
Protopapadakis, E., Voulodimos, A., Doulamis, A. and Camarinopoulos, S. (2017) 'A Study on the Use of Kinect Sensor in Traditional Folk Dances Recognition via Posture Analysis', 10th ACM International Conference on Pervasive Technologies Related to Assistive Environments, 305-10.

Qian, Y. (2013) 'Crossing the Same River Twice: Documentary Re-enactment and the Founding of PRC Documentary Cinema', in Carlos Rojas and Eileen Cheng-yin Chow (eds) The Oxford Handbook of Chinese Cinemas, 590-609, Oxford: Oxford University Press.

Rabinowitz, A. (2015) 'The Work of Archaeology in the Age of Digital Surrogacy', in Brandon Olson and William Caraher (eds) Visions of Substance: 3D Imaging in Mediterranean Archaeology, 27-42, Grand Forks, ND: The Digital Press at the University of North Dakota.

Reichert, R. and Richterich, A. (2015) 'Introduction: Digital Materialism', Digital Material/ ism, 1 (1) 5-17. doi: doi.org/10.25969/mediarep/634.

Rejack, B. (2007) 'Toward a Virtual Reenactment of History: Video Games and the Recreation of the Past', Rethinking History, 11 (3) 411-25.

Richmond, B. (1994) 'Systems Thinking/System Dynamics: Let's Just Get On With It', System Dynamics Review, 10 (2-3), 135-57. doi: 10.1002/sdr.4260100204.

Rokem, F. (2000) Performing History: Theatrical Representations of the Past in Contemporary Theatre, lowa City: University of lowa Press.

Rotman, B. (2002) 'Corporeal or Gesturo-haptic Writing', Configurations, 10 (3) 423-38. doi: 10.1353/con.2004.0005.

Schechner, R. (1993) The Future of Ritual: Writing on Culture and Performance, London: Routledge.

Schneider, R. (2001) 'Archives: Performance Remains', Performance Research, 6 (2) 1008.

(2011) Performing Remains: Art and War in Times of Theatrical Reenactment, New York: Routledge.

(2015) 'New Materialisms and Performance Studies', TDR: The Drama Review, 59 (4) 7-17.

Selby, S. (2000) Chinese Archery, Hong Kong: Hong Kong University Press.

Smith, L. (2006) Uses of Heritage, London: Routledge.

(2011) 'The 'Doing' of Heritage: Heritage as Performance', in Anthony Jackson and Jenny Kidd (eds) Performing Heritage: Research, Practice and Development in Museum Theatre and Live Interpretation, 69-81, Manchester: Manchester University Press.

Sobchack, V. (2006) 'A Leg To Stand On: Prosthetics, Metaphor and Materiality', in Marquand Smith and Joanne Morra (eds) The Prosthetic Impulse: From a Posthuman Present to a Biocultural Future, 17-41, Cambridge, MA: MIT Press.

Stobiecka, M. (2020) 'Towards a Prosthetic Archaeology', Journal of Social Archaeology, 20 (3) 335-52. doi: doi.org/10.1177/1469605320937530. 
Sumara, D.J. and Davis, B. (1997) 'Enactivist Theory and Community Learning: Toward a Complexified Understanding of Action Research', Educational Action Research, 5

(3) 403-22. doi: 10.1080/09650799700200037.

Sundberg, J. (2014) 'Decolonizing Posthumanist Geographies', Cultural Geographies, 21 (1) 33-47.

Taylor, D. (2003) The Archive and the Repertoire: Performing Cultural Memory in the Americas, Durham, NC: Duke University Press.

(2010) 'Save As... Knowledge and Transmission in the Age of Digital Technologies', Imagining America, 7.

(2016) 'Saving the "Live"? Re-Performance and Intangible Cultural Heritage', Études Anglaises, 69 (2) 149-61. https://www.cairn.info/revue-etudes-anglaises2016-2-page-149.htm.

Todd, Z. (2016) 'An Indigenous Feminist's Take on the Ontological Turn: "Ontology" is Just Another Word for Colonialism', Journal of Historical Sociology, 29 (1) 4-22.

Vawda, S. (2019) 'Museums and the Epistemology of Injustice: From Colonialism to Decoloniality', Museum International, 71 (1-2) 72-9. doi: 10.1080/13500775.2019.1638031.

Vowinckel, A. (2009) 'Past Futures: From Re-enactment to the Simulation of History in Computer Games', Historical Social Research, 34 (2) 322-32.

Wei-Ming, T. (1992) 'A Confucian Perspective on Embodiment', in Drew Leder (ed) The Body in Medical Thought and Practice, 87-100, Dordrecht: Springer. doi: doi. org/10.1007/978-94-015-7924-7_6.

Whatley, S., Cisneros, R. K. and Sabiescu, A. (2018) 'Introduction', in Sarah Whatley, Rosamaria K. Cisneros and Amalia Sabiescu (eds) Digital Echoes, 1-7, Cham: Springer.

Winter, J. (2020) 'Unfinished Business: Remembering the Great War between Truth and Reenactment', Transactions of the Royal Historical Society, 30, 119-40. doi:10.1017/ S0080440120000067.

Witcomb, A. (2007) 'The Materiality of Virtual Technologies: A New Approach to Thinking about the Impact of Multimedia in Museums', in Fiona Cameron and Sarah

Kenderdine (eds) Theorizing Digital Cultural Heritage: A Critical Discourse, 35-48, Cambridge, MA: MIT Press.

Wu, Z. (2012) 'Transdisciplinary and Cross-Cultural Turn of Critical Discourse Studies: A Case of Remaking Chinese Cultural Heritage Discourse', Journal of Guangdong University of Foreign Studies, 6.

Yan, H. (2016) 'World Heritage and National Hegemony: The Discursive Formation of Chinese Political Authority', in William Logan, Máiréad Nic Craith and Ullrich Kockel (eds) A Companion to Heritage Studies, 229-42, Oxford: Wiley Blackwell.

You, Z. (2015) 'Shifting Actors and Power Relations: Contentious Local Responses to the Safeguarding of Intangible Cultural Heritage in Contemporary China', Journal of Folklore Research, 52 (2-3) 253-68.

Zhang, Y. (2021) 'Historical Explanation and Historical Re-enactment: Reshaping the Image of Duke Zhuang in the First Year of Duke Yin's Time (722 BC)', (Chinese) Journal of Shanxi University (Philosophy and Social Science Edition), 15 January. 
Zhou, Y., Sun, J. and Huang, Y. (2019) 'The Digital Preservation of Intangible Cultural Heritage in China: A Survey', Preservation, Digital Technology and Culture, 48 (2) 95-103. doi: doi.org/10.1515/pdtc-2019-0004.

Zhu, Y. (2014) 'Cultural Effects of Authenticity: Contested Heritage Practices in China', International Journal of Heritage Studies, 21 (6) 594-608. doi: 10.1080/13527258.2014.991935.

Ziegler, C. (2016) 'William Forsythe's Improvisation Technologies and Beyond: A Short Design History of Digital Dance Transmission Projects on CD-ROM and DVD-ROM, 1994-2011', in Maaike Bleeker (ed) Transmission in Motion The Technologizing of Dance, 41-52, London: Routledge.

\section{Authors}

Sarah Kenderdine

ORCID iD: https://orcid.org/0000-0002-7190-9946

École Polytechnique Fédérale de Lausanne (EPFL)

Switzerland

Lily Hibberd

ORCID iD: https://orcid.org/0000-0002-0816-8583

Université de Paris

France

Bio Statement:

Lily Hibberd is Adjunct Lecturer at UNSW Sydney and Postdoctoral Fellow at Université de Paris.

Jeffrey Shaw

City University, Hong Kong

Hong Kong

Bio Statement

Jeffrey Shaw is Chair Professor of Media Art, City University in Hong Kong. 